\title{
A modified heterotopic heart transplantation in the rat - as an important model in experimental regeneration and replacement of the failing organ
}

\author{
Joanna E Śliwka', Mirosław Tyrpieñ ${ }^{2}$, Piotr M. Wilczek ${ }^{3}$, Marian Zembala ${ }^{4}$, Piotr Przybyłowski ${ }^{5}$ \\ ${ }^{1}$ Department of Cardiac Surgery, Transplantology and Mechanical Circulatory Support in Children, Silesian Center for Heart \\ Diseases, Zabrze, Poland \\ ${ }^{2}$ Department of Environmental Medicine and Epidemiology, Medical University of Silesia, Zabrze, Poland \\ ${ }^{3}$ Foundation for Cardiac Surgery Development, Zabrze, Poland \\ ${ }^{4}$ Department of Cardiac Surgery, Transplantology and Vascular Surgery, Medical University of Silesia, Zabrze, Poland \\ ${ }^{5}$ First Chair of General Surgery, Jagiellonian University Medical College, Krakow, Poland
}

Kardiochir Torakochir Pol 2020; 17 (3): 149-154

\begin{abstract}
The qualification of new knowledge is one of the oldest problems in experimental medicine that provides a link between fundamental discovery, hypothesis, 'proof of concept' preclinical studies and development of clinical trials. The biggest challenge in animal models is the proper evaluation of all the aspects that are crucial in specific studied pathologies as well as the prediction of their progression. The aim of this review was to describe and discuss the rat animal model of heart transplant. The rat model of heart transplantation is an excellent yet underestimated method of research of prevention, monitoring and treatment of acute and chronic, immune and nonimmune response to organ transplantation. Despite being a technically and logistically demanding model, it provides a tool for reproducible experiments with longterm animal survival and excellent graft survival.
\end{abstract}

Key words: animal model, heart transplantation, sex differences.

\section{Introduction}

The qualification of new knowledge is one of the oldest problems in experimental medicine. Producing a standardized tool to test the hypothesis has been a primary goal of scientific research. The definition of "experimental model" has been evolving through various areas of research, from "the simple representation of the reality derived only from abstraction" through "an act of spirit in which we can inspire ourselves" (from the $17^{\text {th }}$ century, Blaise Pascal) to the modern one, which describes it as "any example that uses the analytical method for research and hypothesis inquiry". Experimental medicine provides a link between fundamen-

\section{Streszczenie}

Określenie jakości i poziomu przydatności nowej wiedzy jest jednym z najstarszych problemów medycyny eksperymentalnej, która zapewnia powiązanie między fundamentalnym odkryciem, hipotezą, przedklinicznymi badaniami „dowodu słuszności” a rozwojem badań klinicznych. Największym wyzwaniem w modelach zwierzęcych jest właściwa ocena wszystkich aspektów, które są kluczowe w poszczególnych badanych patologiach, a także przewidywanie ich progresji. Celem tej pracy było opisanie i omówienie modelu przeszczepu serca u szczura. Model ten jest doskonałą, lecz nadal niedocenianą, metodą badań w zapobieganiu, monitorowaniu, a także leczeniu ostrej oraz przewlekłej odpowiedzi immunologicznej i nieimmunologicznej po przeszczepieniu narządu. Mimo że jest to model wymagający pod względem technicznym i logistycznym, umożliwia uzyskać powtarzalne eksperymenty z długoterminowym przeżyciem nie tylko zwierząt, lecz także przeszczepionych narządów.

Słowa kluczowe: model zwierzęcy, przeszczepienie serca, różnice płci.

tal discovery, hypothesis, 'proof of concept' preclinical studies and development of clinical trials [1].

Using experimental animal models in medical research not only furthers the understanding of the mechanism and progression of the disease or any physiological disturbances, but also provides the possibility of introducing new methods of surgical, pharmacological or other treatments that offer enhanced patient outcomes (efficacy and safety). The typical model involves animals in which physiological or pathological processes are sufficiently similar to those in humans and are either induced or occur naturally. The biggest challenge in animal models is the proper evaluation of

Address for correspondence: Joanna E. Śliwka, Department of Cardiac Surgery, Transplantology and Mechanical Circulatory Support in Children, Silesian Center for Heart Diseases, 9 M. Skłodowskiej-Curie St, 41-800 Zabrze, Poland, phone: +48 501 324 251, e-mail: jsliwka@sccs.pl Received: 23.07.2020, accepted: 15.08.2020. 
all the aspects that are crucial in specific studied pathologies as well as the prediction of their progression.

\section{Aim}

The aim of this review was to describe and discuss the rat animal model of heart transplant, which, with the proposed modification, provides an excellent and reproducible modality to study organ preservation and effective replacement.

\section{Discussion}

From all causes of different organ failure, cardiovascular diseases are the leading cause of morbidity and death in developed countries. The different multifactorial pathologies, including congenital and acquired anatomical disturbances in blood flow and atherothrombosis of the coronary arteries causing ischemic heart disease, are the reasons for heart failure at the end stage. Heart transplant is an accepted treatment modality in the end stage of heart failure.

Transplantology is the field of medicine interested in replacing or adding cells or entire organs in order to restore the function of the human body. The main problem in transplantation procedures using any cells or organs taken from different species is the immunological response to the foreign tissue. Autotransplantation, the process in which the transplanted tissue comes from the recipient, is the only method completely safe from rejection.

There is no immunological acceptance of the living tissue transplanted from different species, a procedure called xenotransplantation. In those experimental models a strong anti-rejection treatment is used that often complicates the postoperative period with its severe side effects, and ultimately a loss of the transplanted organ or tissue occurs.

The fully accepted method of obtaining organs is procurement from a representative of the same species, called allotransplantation. However, even the allografts are not immunologically compatible, and an anti-rejection treatment must be implemented, although it generally provides better results and less severe side effects. At the time of transplantation, the battle between the immune response of the recipient and the side effects of the pharmacological treatment begins, and it must be balanced in order to keep the graft fully functional. The survival of the graft is unpredictable and depends on the various significant and chronic changes in its physiology. The unique immune response depends not only on an immunological compatibility between the donor and the recipient, but also on the age, gender and comorbidities that have an impact on immunological condition. In the era of organ donor shortages, medical research is striving to find the safest and most efficient method to preserve graft function as long as possible.

In 1905, Alexis Carrel worked on an animal model of heterotopic heart transplant without success, and it was not until 55 years later that Richard R. Lower and Norman E. Shumway successfully performed an orthotopic heart transplant in a canine model. In 1967, Christian N. Barnard was the first to transplant the human heart with success following his work on animal models. Since then research in heart transplantation has developed enormously.

Nowadays, animal models of organ and tissue transplantation provide the ultimate preclinical assessment for the study of rejection mechanisms. Both large and small animals have been used in this research. There are three main factors in choosing the animal model: first, the scientific hypothesis, second, the laboratory's ability to maintain the selected animal species, and third, the degree of similarity to the human anatomy and physiology. The use of either small or big animals can be limited by the technical problems due to specific laboratory equipment and the researchers' skills. All these aspects should be taken into consideration when choosing the animal model [2].

There are two main models of heart transplantation: orthotopic (the donor heart is placed in an anatomically correct position) and heterotopic (the donor heart is placed in a location other than the mediastinum). The orthotopic transplantation is a gold standard for the study of heart transplantation. It requires not only the use of cardiopulmonary bypass, but also a high level of surgical skills and larger animals, being almost impossible to perform in rodents. This model has traditionally been chosen for the study of organ preservation, immunology, graft rejection and ischemia/reperfusion injury.

While heterotopic heart transplantation is uncommonly used in transplantology research due to the nonphysiological blood flow (limited to coronary arteries and venous systems), it is widely used for studies of ischemia/reperfusion injury, immunosuppression, prevention of rejection, or graft coronary vasculopathy evaluation. The main technical difficulty comes from the need to use microsurgery techniques, especially in rodents. The undeniable advantage of this model is that the recipient may remain completely healthy whether or not the heterotopic donor heart survives, whereas the transplanted heart behaves as an aorto-caval fistula of little hemodynamic consequence to the recipient.

Rats are popular in transplantology research because of their size, low maintenance of the model, reproducibility, low cost and ease of handling in most laboratories: the rat reaches sexual maturity between the $80^{\text {th }}$ and $100^{\text {th }}$ day of life and the fertility decreases after 5-6 l; the pregnancy lasts 21-23 days and depending on the strain, 4-16 pups are born. There are a variety of strain types that provide researchers with many options when designing experiments. Because of the homozygosity of the strains, it is necessary to take into account their adaptability impairment in comparison with unselected strains (heterozygotes-wild strains), which requires the creation of optimal and stable handling conditions.

To avoid intra-species variability in medical research inbred strains (genetically almost identical) are widely used. The inbred strains include consomic (chromosomal substitution), congenic (chromosomal region substitution), recombinant inbred, transgenic and mutant strains. 
For transplantology research, a simple inbred strain is used to reduce acute intra-species dependent immunology responses as well as the need for the administration of antirejection drugs. To achieve a simple inbred strain at least 20 generations of brothers and sisters have to be mated, and after that each individual can be treated effectively as a clone (at which point at least $98.6 \%$ of the loci in an individual of the strain will be homozygous) [3]. The knock-out rat is a genetically engineered rat with a single gene turned off through a targeted mutation. Because the technology of creating knock-out rats is very recent, models using mutant rats are only just emerging.

Despite all the limitations the rat model is still attractive because of the availability of a larger number of genetically well-characterized inbred and congenic strains.

Most of the strains in research are derived from the albino Wistar rat. Other common strains are Sprague-Dawley, Fisher 344, Holtzman albino, Long Evans, and Lister black hooded rats. To avoid complications, the study design should consider the appropriate strain such as a strain resistant to respiratory infections.

The rat heterotopic heart transplantation is a reproducible model for studies on transplantation immunology, mechanisms and treatment of allograft acute rejection and vasculopathy as a result of chronic rejection. This model is attractive because it uses a vascularized organ, which is more relevant to clinical transplantation than tissue grafts.

\section{Operative techniques}

The technique of heterotopically transplanting fully vascularized hearts from one rat into the abdomen of another rat was originally described in 1933 by Mann, introduced by Abbott et al. [4]. They however were dealing with paraplegia as the main complication of the procedure with resultant wastage of time and animals. Finally, in 1969 Ono and Lindsay introduced an improved model of the heterotopic heart transplantation that minimized the risk of paraplegia. In that model, the heart is harvested from the donor after heparinization and preserved in cardioplegia. After recipient abdominal vessel preparation and clamping, the heart is placed transversely in the left side of the abdominal cavity and donor aorta and pulmonary artery are connected end-to-side to the recipient aorta and inferior vena cava (IVC) using a running suture. This technique requires microsurgical equipment including an operative microscope, surgical instruments (jeweler's forceps, angled Castroviejo iris scissors and straight (astroviejo needle holder) and very fine sutures, e.g. 10-0, usually used in ophthalmology. After releasing the clamps, the heart starts to contract spontaneously. In order to be successful, the time of the vessel clamping during implantation should not exceed 30 minutes. The operative technique is described in detail in their publication and is still widely used [5].

Despite its simplicity and reproducibility, the model has limitations as a consequence of a lack of hemodynamic work of the left ventricle (LV): stroke volume and LV pressure close to zero, deep structural and metabolic changes, different myosin structure, impaired enzymatic activity, reduced total protein content in the heart muscle and changes in heart weight. This results in heart failure and finally graft atrophy [6]. Smith et al. reported a $15 \%$ to $25 \%$ reduction in graft size relative to the native heart in 14 days and a $30 \%$ to $60 \%$ reduction by day 60 [7].

In 1991, Klein et al. presented a modification of Ono's model. They proposed the insertion of a balloon to the left ventricle to sustain the isovolumic work [8]. This solved the problem with atrophy but did not preserve the ventricle from fibrosis and restriction. To improve the filling of the ventricle with blood, an aortic regurgitation was created by puncturing one of the aortic cusps. This modification of the model was described by Spencer et al. [6] and greatly changed the LV loading and enforced the ventricle to actively pump the returning blood. The degree of aortic regurgitation and the impact on graft workload needed to be further improved [9].

Yokoyama et al. [10] presented a different model of loaded LV-ASD creation, resection of the tricuspid valve, pulmonary artery ligation-donor aorta anastomosis to the recipient's abdominal aorta and the donor right atrium to the recipient's IVC respectively. The main difference is in oxygenation in the coronary circulation (Figure 1).
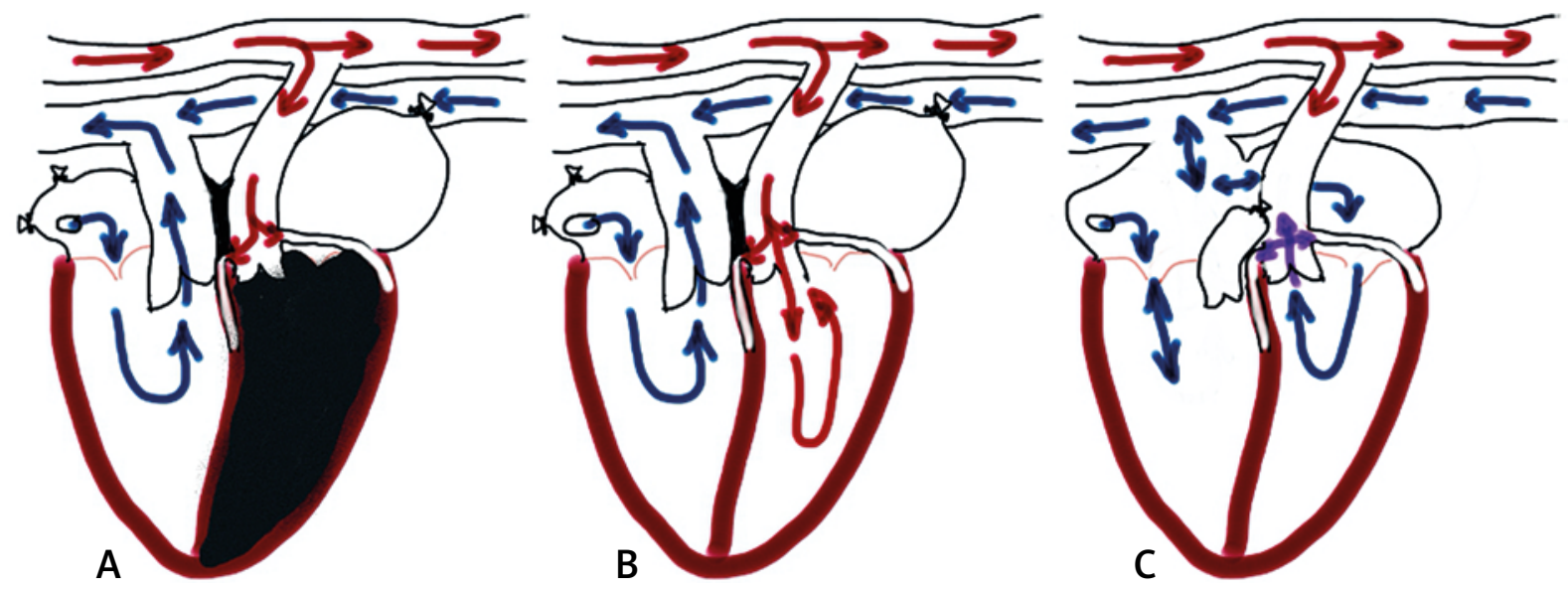

Figure 1. Models of the heart transplant: A - Ono. B - Spencer and Śliwka. C - Yokoyama 
Tang-Quan et al. [11] compared non-volume-loaded to Yokoyama's volume-loaded model of heterotopic heart transplantation and confirmed in both echocardiography and Langendorff perfusion that those volume loaded hearts undergo chronic ischemia because of coronary perfusion with partly deoxygenated blood and are not recommended in preclinical transplant studies.

Therefore, the most optimal model requires the oxygenated coronary blood flow and ventricle loading, as described by Śliwka et al. and Spencer et al. [6, 9].

All the modifications resulted in a well-established heterotopic heart transplant model of low mortality and extended graft survival that facilitates research of functional integrity of a whole organ and the effects of immunosuppressive drugs and chronic rejection.

\section{Function monitoring}

\section{Palpation}

There are two basic methods used to monitor the function of the heterotopically transplanted heart, the everyday palpation through the abdominal wall and electrocardiography at defined points in the follow-up period. Palpation of the strength of cardiac contractility is assessed on a 4-degree scale: 4+ the strongest and 1+ the weakest. The first manifestation of acute rejection is a decline in strength and occurs six to eight days after heart transplantation ("time of impulse decline", TID) of an $\mathrm{H}-2$ and non$\mathrm{H}-2$ mismatched graft if no immunosuppression was used. Usually 2-3 days after TID the heartbeat is hardly or not palpable and the rejection process is completed [4].

\section{Electrocardiography}

The electrocardiographic signs of the rejection are voltage deflections of less than $3 \mathrm{~mm}$ in each electrical vector tested. These methods of graft rejection assessment are reproducible and corelate well with graft histology [12].

\section{Ultrasound evaluation}

The serial echocardiography is not sensitive enough to detect and assess early signs of graft rejection. The ventricular wall thickness and ejection fraction remain almost unchanged at the early phase of intra-graft immunological response. Fischer et al. presented a novel imaging platform to diagnose and monitor acute and chronic graft rejection with the possibility of predicting this process. They used contrast-enhanced ultrasonography (CEUS) in combination with gas-filled microbubbles to detect and assess the changes in micro-vascular perfusion as the effect of the rejection process and confirmed its utility in a murine model of heart transplant research. Furthermore, they created a high-resolution perfusion map of CEUS signals to detect impaired blood flow in the graft microvasculature [13].

Advances in ultrasound technology, e.g. VEVO 3100, including ultra-high-frequency transducers up to $70 \mathrm{MHz}$, improvements in signal processing and novel post-acquisition analysis such as diastolic dysfunction, cardiac strain (longi- tudinal, radial, and circumferential synchrony and deformation globally or regionally) as well as image-guided cardiac injections and assessment of myocardial oxygen saturation, have all improved the imaging quality and utility of ultrasound systems.

Nonetheless, standard ultrasound with assessment confined to only the left ventricle ejection fraction is still widely used in heart transplant research.

\section{Isolated heart perfusion}

For better evaluation of the graft function, the isolated heart perfusion is one of the most popular experimental models in regard to the quality and quantity of the provided data (spectrum of pharmacological, biochemical, physiological and morphological measurements). The main investigational advantage is that the measurements can be made in the absence of the confounding effects of other organs and circulating neurohormones. For both Langendorff perfusion (isolated retrograde perfusion) and working heart special equipment and experience are required to record and analyze multiple cardiac parameters such as left ventricular pressure, perfusion pressure, coronary flow, cardiac electrical activity and heart rate in real time. The isolated heart can be used in transplantology research to study coronary reactivity, endothelial and smooth muscle function as a consequence of the graft vasculopathy and ischemia [14].

\section{Rejection in rats}

Most rodents have major histocompatibility complex (MHC) variants similar to those of humans, determining the immune responsiveness of different strains to isolated antigens and inducing rejection. In rats it is called RT1 with the location of 20p12. Gene products of different regions within the rat MHC-class I or II antigens influence the type of rejection if an organ is transplanted across isolated class I or class II disparities. The RT1 complex encodes two class I molecules, RT1.A and RT1.C, and two class II molecules, RT1.B and RT1.D. Barran and McMaster described the isolation of the RT1.B $\alpha$ gene in Sprague-Dawley rats using RT1.B $\alpha$ chain cDNA as a hybridization probe. They determined the coding and the majority of the intron DNA sequence and confirmed that this gene is equivalent to that of $\mathrm{H}-2$ in mice and HLA $\alpha$ chain in humans [15].

Transplantation across full MHC incompatibilities can evoke acute rejection. Guttman described hyperacute cardiac allograft rejection, which was characterized by edema, cyanosis, arrhythmia, ventricular fibrillation and finally asystole in 4 hours (maximum in 24 hours) after heterotopic heart transplantation in recipients previously sensitized with skin transplantation [16]. As mentioned above, the acute rejection can be induced across either a class I or class II disparity, but class II disparities present a stronger barrier to heart transplantation and limit the survival of the graft to 10 days. But even in full compatibility in MHC of the donor and recipient, the discrepancy of survival time varies depending on the organ transplanted. Of note is 
that the amount of the lymphatic tissue transplanted with the heart is considerably smaller than in pancreatic or skin transplant, resulting in different expression of the $\mathrm{MHC}$ antigens. There is also a correlation between the strength of the response against a specified $\mathrm{MHC}$ antigen and the strain. Previous observations $[12,16]$ showed that the $\mathrm{ACl}$ strain is highly immunogenic while the Brown Norway (BN) rat is a low responder in proliferative reactions to alloantigens in vitro. This observation must be considered when planning future research.

Despite the rapid rejection of MHC-mismatched heart allografts alone, differences in non-MHC histocompatibility antigens also influence the graft survival. The strength of the non-MHC barrier is controlled by the immune response (Ir) gene, which is extremely variable even from one tissue to another and may depend on the number of dendritic cells transferred within the transplanted organ. Removal of these "passenger cells" may reduce the graft immunogenicity [17].

As previously mentioned, concerning MHC full compatibility Klempnauer et al. described the quicker pancreas allograft rejection in the same non-MHC disparate strain combination [18]. The number of non-MHC disparities can cumulate and determine the strength of the organ rejection. This process was explained by either additive or independent interactions, but not by synergy. However, Klempnauer et al. described a synergistic effect between non-MHC and class I antigens on acute graft rejection [19]. Research concerning MHC and non-MHC disparities confirmed that there are unpredictable numbers of possible combinations of antigens and their products to induce heart rejection. The recommended solution to avoid gene incompatibilities responsible for acute rejection is to use inbred strains, which behave like clones. This may help to understand the mechanisms of chronic heart rejection that is unrelated to $\mathrm{MHC}$ and non-MHC (like Ir in rats) genes. The most interesting are differences in the immunological response depending on sex combination of the donor and recipient, which were observed but difficult to study in heterogeneous species such as humans.

\section{Histopathology of the rejection in rats}

The histological scales to assess rejection in explanted grafts are the modifications of the International Society for Heart and Lung Transplantation rejection scale. The most popular is a 3-grade scale described by Barak et al. where, after harvesting, preserving in 5\% formalin and finally embedding the grafts in paraffin, hematoxylin and eosin staining is performed. The samples are scored as follows: 0 - normal; 0.5 - perivascular infiltrate, focal; 1 - perivascular and interstitial infiltrate, focal; 1.5 - infiltrate, confluent; 2 - infiltrate associated with necrosis of myocytes; 2.5 diffuse infiltrate, necrosis and edema; 3 - diffuse infiltrate, necrosis, edema and hemorrhage [20].

The scale modified by Takami et al. has 5 grades (without grade 2) and is widely used among researchers [21].

\section{Sex differences}

There are several publications concerning gender influence on results in all solid organ transplantation [22-29] as a non-immunologic factor. Regitz-Zagrosek et al. showed that the sexes differ in distribution of risk factors of heart diseases: women more frequently suffer from diabetes and hypertension while men more frequently exhibit coronary heart disease and dilatative cardiomyopathy. There is also a difference in structure - women's hearts are stiffer and smaller, and during aging the processes of fibrosis, apoptosis and hypertrophy are less pronounced. Generally, the potential causes of this pathway are estrogens; they protect myocytes against calcium load induced by hypoxia, increase availability of nitric oxide (NO) and impact vasodilatation, downregulate fibroblast proliferation and gene expression of collagens I and III in females in vitro and decrease ventricular remodeling by matrix metalloproteinase 2 (MMP-2) gene expression inhibition [30].

Functional receptors for both estrogen and androgen have been found in human and rat hearts: in vascular endothelium, smooth muscle cells of vessel walls, cardiac fibroblasts and myocytes, and they influence the effect of the sex hormones on the heart. The processes mentioned above impact the heart metabolism and may influence the result of heart transplantation if there is a sex mismatch between donor and recipient. Takami et al. [21] also confirmed that pharmacokinetics of cyclosporine, one of the immunosuppressive medications used in the rat model of heart transplant, differs significantly; blood level in females was almost half that of males with contribution to more vigorous heart rejection in females. In a subgroup of orchiectomized rats, the suspected immunosuppressant and immune modulation role of the androgens was observed. They concluded that female recipients are at greater risk of heart rejection irrespective of donor gender and they may require stronger immunosuppression treatment. Other researchers also observed that females are better donors and males are better recipients regardless of the research protocol.

The sex difference of immune reaction to allograft transplantation is a matter of controversy in humans and consequently there is no gender matching between donor and recipient. In the rat model, using syngeneic animals, the immune response based on MHC and non-MHC disparity can be minimized and non-immunologic factors (such as gender-dependent response) investigated. Also, use of rat females not presensitized with pregnancies diminishes the risk of acute humoral rejection.

In the shortage of human donors and conflicting results in retrospective data, research concerning gender-related disparities in matched groups is not possible from an ethical point of view.

\section{Conclusions}

The rat model of heart transplantation is an excellent yet underestimated method of research of prevention, monitoring and treatment of acute and chronic, immune 
and non-immune responses to organ or tissue transplantation. It provides the possibility of combining donor and recipient sex, and syngeneic or allogenic strains. Despite being a technically and logistically demanding model, it provides a tool for reproducible experiments with longterm animal survival and excellent graft survival.

\section{Disclosure}

The authors report no confflict of interest.

\section{References}

1. Ferreira LM, Ferreira LRK. Experimental model. Historic and conceptual revision. Acta Chirurgica Brasileira 2003; 18.

2. Robinson N, Souslian L, Gallegos RP, et al. Animal models for cardiac research. In: Handbook of Cardiac Anatomy, Physiology, and Devices. Iaizoo PA (ed.). Springer 2005.

3. Dwinell MR. Online tools for understanding rat physiology. Brief Bioinform 2010; 11: 431-439.

4. Abbott CP, Lindsey ES, Creech O Jr, Dewitt CW. A technique for heart transplantation in the rat. Arch Surg 1964; 89: 645-652.

5. Ono K, Lindsey ES. Improved technique of heart transplantation in rats. J Thorac Cardiovasc Surg 1969; 57: 225-229.

6. Spencer AU, Hart JP, Cabreriza SE, et al. Aortic regurgitation in the heterotopic rat heart transplant: effect on ventricular remodeling and diastolic function. J Heart Lung Transpl 2003; 22: 937-1045.

7. Smith JA, Mottram PL, Mirisklavos A, et al. Isograft and allograft control studies for murine cardiac transplantation. Transplant Proc 1987; 19: 1039-1042.

8. Klein I, Hong C, Schreiber SS. Isovolumic loading prevents atrophy of the heterotopically transplanted rat heart. Circ Res 1991; 69: 1421-1425.

9. Śliwka J, Dołoszyńska A, Sokal A, et al. Introducing an experimental heterotopic heart transplantation model in rat in the Cardiovascular Research Laboratory of the Silesian Centre for Heart Diseases in Zabrze. Kardiochir Torakochir Pol 2008; 5: 171-175.

10. Yokoyama H, Ohmi M, Murata S, et al. Proposal of a working left heart model with a heterotopic transplantation technique in rats. J Heart Lung Transplant 1995; 14: 706-712.

11. Tang-Quan KR, Bartos J, Deuse T, et al. Non-volume-loaded heart provides a more relevant heterotopic transplantation model. Transpl Immunol 2010; 23: 65-70.

12. Madsen JC, Morris PJ, Wood KJ. Immunogenetics of heart transplantation in rodents. Transpl Rev 1997; 11: 141-150.
13. Fischer K, Ohori S, Meral FC, et al. Testing the efficacy of contrast-enhanced ultrasound in detecting transplant rejection using a murine model of heart transplantation. Am J Transplant 2017; 17: 1791-1801.

14. Sutherland FJ, Hearse DJ. The isolated blood and perfusion fluid perfused heart. Pharmacol Res 2000; 41: 613-627.

15. Barran PA, McMaster WR. DNA sequence analysis of the rat RT1.B alpha gene. Immunogenetics 1987; 26: 56-62.

16. Guttmann RD. A genetic survey of rat cardiac allograft rejection in presensitized recipients. Transplantation 1976; 22: 583-588.

17. Lechler RI, Batchelor JR. Restoration of immunogenicity to passenger celldepleted kidney allografts by the addition of donor strain dendritic cells. J Exp Med 1982; 155: 31-41.

18. Klempnauer J, Steiniger B, Wonigeit K, Gunther E. Genetics of heart allograft rejection in the rat. Transplant Proc 1985; 17: 1897.

19. Klempnauer J, Steiniger B, Luck R, Gunther E. Genetic control of rat heart allograft rejection: effect of different MHC and non-MHC incompatibilities. Immunogenetics 1989; 30: 81-88.

20. Barak JH, LaRaia PJ, Boucher CA, et al. Thallium kinetics in rat cardiac transplant rejection. Transplantation 1988; 45: 687-692.

21. Takami H, Backer CL, Crawford SE, et al. Influence of gender on allograft rejection in a rat heart transplant model. J Heart Lung Transplant 1995; 14: 529-536.

22. Bergenfeldt $H$, Stehlik J, Hoglund $P$, et al. Donor-recipient size matching and mortality in heart transplantation: Influence of body mass index and gender. J Heart Lung Transplant 2017; 36: 940-947.

23. Elmariah S, Goldberg LR, Allen MT, Kao A. Effects of gender on peak oxygen consumption and the timing of cardiac transplantation. J Am Coll Cardiol 2006; 47: 2237-2242.

24. Erinc K, Yamani MH, Starling RC, et al. The influence of donor gender on allograft vasculopathy: evidence from intravascular ultrasound. Transplant Proc 2004; 36: 3129-3131.

25. Ge F, Huang T, Yuan S, et al. Gender issues in solid organ donation and transplantation. Ann Transplant 2013; 18: 508-514.

26. Peled $\mathrm{Y}$, Lavee J, Arad M, et al. The impact of gender mismatching on early and late outcomes following heart transplantation. ESC Heart Fail 2017; 4: 31-39.

27. Tosi L, Federman M, Markovic D, et al. The effect of gender and gender match on mortality in pediatric heart transplantation. Am J Transplant 2013; 13: 2996-3002.

28. Weiss ES, Allen JG, Patel ND, et al. The impact of donor-recipient sex matching on survival after orthotopic heart transplantation. Circ Heart Fail 2009; 2: 401-408.

29. Welp H, Spieker T, Erren M, et al. Sex mismatch in heart transplantation is associated with increased number of severe rejection episodes and shorter long-term survival. Transplant Proc 2009; 41: 2579-2584.

30. Regitz-Zagrosek V, Oertelt-Prigione S, Seeland U, Hetzer R. Sex and gender differences in myocardial hypertrophy and heart failure. Circ J 2010; 74: 1265-1273. 